\title{
The scope and limits of accounting and judicial courts intervention in inefficient public procurement*
}

\author{
Antonio Estache ${ }^{\dagger} \quad$ Renaud Foucart ${ }^{\ddagger}$
}

November 29, 2017

\begin{abstract}
Cost inefficiencies in public procurement tend to come from two sources: corruption (moral hazard) and incompetence (adverse selection). In most countries, audit authorities are responsible for monitoring costs but do not distinguish both sources of inefficiency in their audits. Judicial courts typically rely on these cost audits, but only sanction corruption. In a model of public procurement by politicians, we study how the respective quality of the two courts affects corruption as well as cost efficiency. We find that while better courts have the direct effect of decreasing corruption, they may have a negative indirect effect on the abilities of the pool of politicians, so that the net effect on cost efficiency is ambiguous.
\end{abstract}

Keywords: moral hazard, adverse selection, procurement

JEL: D72, H57, L3

\section{Introduction}

Public procurement represents a very significant share of the value added in every country in the world. In OECD countries, 15 to $25 \%$ of GDP is typically composed of government purchases of goods, equipment, and services; public works; studies; and other activities needed to deliver public services. ${ }^{1}$ Cost inefficiencies are common in these markets, and whether they arise because of corruption, incompetence or simply bad luck often remains an open question. A 2014 study by

*This paper has benefited from financial support from the Chaire Bernard Van Ommeslaghe. We are grateful to Daniel Camos, Estelle Cantillon, Micael Castanheira, Bram De Rock, Pierre Francotte, Jana Friedrichsen, Victor Ginsburgh, Steven Kennedy, Patrick Legros, André Sapir, Richard Schlirf, Johannes Spinnewijn, Tina Soreide and two anonymous referees for useful comments and discussions.

†ECARES, Université libre de Bruxelles and CEPR (aestache@ulb.ac.be)

${ }^{\ddagger}$ Humboldt University, Berlin (renaud.foucart@gmail.com)

${ }^{1}$ OECD statistics, available at: http://stats.oecd.org/ 
PricewaterhouseCoopers $(\mathrm{PwC})$ for the European Union (EU) estimates that bid rigging in public procurement affects $48 \%$ of auctions. ${ }^{2}$ The inefficiencies arising from corruption and incompetence in procurement represent 10 to $30 \%$ of the costs of publicly funded construction projects (OECD, 2016).

In most countries, a key element of the policies adopted to reduce the risks of corrupt and incompetent practices is reliance on internal government controls (OECD, 2016). Such controls tend to be housed within the procurement entities themselves but are also often complemented by independent government auditing units. ${ }^{3}$ In 2014, the European Court of Auditors (ECA) ${ }^{4}$ identified problems in about $40 \%$ of the procurement projects undertaken with EU funds. As only corruption is actually illegal, it is generally rational for any individual involved in an action identified by auditors as irregular to claim incompetence rather than dishonesty. To find a politician or political appointee guilty, therefore, the assessment of an accounting court must be complemented by the assessment of a judge.

In this paper, we analyze the respective influence of the quality of the judicial system and the accounting courts on the cost efficiency of public procurement. We find that increasing the quality of both courts helps decrease procurement costs when the main driver of high costs is corruption. When the main problem is incompetence, however, better courts sometimes make things worse. These results are driven by the skills and honesty of the politicians (or political appointees) responsible for the management of the procurement process. This insight contributes to the literature on the endogenous selection of politicians (Caselli and Morelli, 2004; Besley, 2005; Poutvaara and Takalo, 2007). It does so by taking into account the difficulties of identifying the source of cost overruns (Bandiera et al., 2009), focusing on the need to distinguish between incompetence and corruption and on the role of judicial and accounting courts in improving the overall efficiency of procurement.

We assume that citizens differ in ability and choose when to join the pool of politicians or political appointees (denoted through the paper as "politicians"). We treat ability as a single dimension, so that more able politicians have a higher opportunity cost of being in office (a standard assumption in the literature). We also assume that more able politicians are more often in a position to benefit from corruption. One reason for this is that they have a better understanding of

\footnotetext{
${ }^{2}$ PwC (2014), Public Procurement: costs we pay for corruption.

${ }^{3}$ For instance, the Government Accountability Office for the U.S. federal government, the National Audit Office in the United Kingdom, the Cour des Comptes in France or Belgium, and the Tribunal de Cuentas in Spain. Herein we use the term "court" to refer to such audit authorities, contrasting, for example, "accounting courts" with "judicial courts."

${ }^{4}$ European Court of Auditors (2014), Audit of public procurement by the European Court of Auditors, Berlin, November 14.
} 
the process, which is directly linked to the ability to manage it. Another is that they are more likely to have connections at a higher levels: Gagliarducci et al., 2010 for instance, show that in Italy high-income citizens entering politics tend to be less dedicated than those of more modest means and to make more money from outside activities. ${ }^{5}$ Our distinction between incompetence and corruption is very close to the idea of active and passive waste in Bandiera et al. (2009), who show that $83 \%$ of the waste in public purchases of standardized goods in Italian municipalities is the consequence of passive waste, described as a combination of incompetence and the costs of regulation. In Russia, Best et al. (2017) show that more than half of the variation in prices paid for an identical good can be explained by differences in ability of the bureaucrats.

While we find that the direct effect of both better judicial and accounting courts is to decrease the probability of corruption, we also identify indirect and possibly detrimental effects on the ability of politicians. Good judges may decrease the quality of the pool of politicians for three reasons. First, because better judges decrease the probability of being wrongfully convicted for corruption, they protect the least able politicians and make politics more attractive to them. Second, as the least able politicians have fewer opportunities to benefit from corruption, better judges decrease the relative advantage of the most able politicians if corruption is an important share of politicians' income. Third, if corruption is not an important source of income, better judges make politics more attractive to the marginal citizen, indifferent between entering politics or not. If the most able citizens are politicians, the marginal politician is of lesser ability than the average and her entry decreases the quality of the pool. This last effect is reminiscent of the possibility of a detrimental impact of wages on the quality of politicians documented in Poutvaara and Takalo (2007).

Better accounting courts may similarly lower the quality of the pool of politicians for two reasons. First, as with good judges, good accounting courts may decrease the relative benefit of highly able citizens if corruption is an important source of income. Second, better accounting courts decrease the share of judicial mistakes affecting higher-ability citizens, but raise the share of mistakes affecting the least able citizens. If only the least able citizens enter politics and the marginal politician is of low ability, better accounting courts make politics less attractive to her, and the quality of politicians decrease.

More generally, we find that an "ideal" institutional design combines sufficiently good accounting courts, high punishment for corrupt politicians and, somewhat counter intuitively, suffi-

\footnotetext{
${ }^{5}$ The idea that more able politicians have more room for corruption is at the basis of the so-called "tradeoff hypothesis" (Winters and Weitz-Shapiro, 2013) according to which some voters would be willing to accept more corruption in exchange of more competence.
} 
ciently bad judicial courts responsible for punishing corrupt politicians. Within this institutional framework, we also show the local conditions under which expected procurement costs can be cut through a marginal increase in the quality of the two types of courts, a change in the wages of politicians and more severe levels of punishment.

These broad conclusions rest on four important modeling assumptions which we relax in various extensions of the model. First, we assume that each citizen choosing to become a politician is elected with equal probability, implying that voters cannot screen based on skills. We show in section 6.1 that assuming, instead, that voters screen the most able candidates would mechanically decrease the importance of the selection problem. ${ }^{6}$ The extent to which voters actually assess the competence of their politicians is thus crucial but easily overestimated. For instance, Todorov et al. (2005) show that "inferences of competence, based solely on the facial appearance of political candidates and with no prior knowledge about the person, predict the outcomes of elections for the U.S. Congress even after voters were given the possibility to correct their vote after receiving additional information on politicians' competence."7 Hence, unless voters manage to correctly identify the most able citizens by assessing their physical appearance, ${ }^{8}$ elections alone do not suffice to screen the most able candidates.

Second, we define an increase in the quality of a court as a symmetric decrease in the share of false positives and false negatives in its judgments. In practice, this corresponds to giving more resources or autonomy to those courts. Alternatively, it is possible to study the severity of courts, defined as decreasing the number of false negatives at the cost of increasing the number of false positives. We show in section 6.2 that judicial severity does not affect the pool of politicians in the same way as judicial quality. In other words, while better judges make politics more attractive to the least able citizens, more severe judges make politics less attractive to everyone.

Third, we consider ability as a single dimension: a more able politician is better at delivering public goods at low cost, has more outside options, and is more often in a position to benefit from bribes. In section 6.3, we study a variant of the model in which the ability to benefit from corruption is independent from the ability to deliver projects at low cost. In that case, the least able

\footnotetext{
${ }^{6}$ The same holds for corruption. A study of Brazil by Winters and Weitz-Shapiro (2013) concludes that the lack of credible information on corruption explains the inability of voters to punish it. The question of how voters should gather such information remains open, however, as discussed for instance by Lambert-Mogiliansky (2015).

${ }^{7}$ A perhaps even more striking example is given in Antonakis and Dalgas (2009), who show that a sample of children asked to choose the ideal "captain of their boat" from a picture predicted correctly $71 \%$ of the results of the French parliamentary elections, with a rate of successful prediction that was undistinguishable from that of adults.

${ }^{8}$ The problem we study would matter less if the beauty premium (see also Hamermesh et al., 1994) is a strong predictor of the ability to deliver a public procurement project at low cost. Berggren et al. (2010), show that perception of competence and beauty are strongly correlated; Berggren et al. (2017) demonstrate that physical appearance also helps identify the ideology of a candidate.
} 
politicians are the ones who accept the most bribes, because they know that, without corruption, they are more likely to deliver at high cost and to be victims of judicial errors. Even in this case, it remains possible for better courts to lower the quality of the pool of politicians, because of the degree to which better judges protect the least able politicians from judicial errors.

Fourth, we rule out the fact that some politicians are genuinely honest and derive no utility from bribes (defined broadly to cover conflicts of interests). In section 6.4, we consider politicians with different preferences for corruption. If the most able politicians are also more honest, they are also hurt less by a decrease in corruption, neutralizing one of the reasons why better courts may lower the ability of politicians.

We review the relevant literature in the next section. Section 3 presents the model and the equilibrium of the game. We provide comparative statics on the impact of the quality of the different courts in Section 4. Section 5 studies the impact of policy changes on cost efficiency, corruption and the share of judicial errors. We discuss the robustness of our results to different assumptions in section 6 and conclude in section 7 .

\section{Related Literature}

Our contribution looks into institutional failures that allow inept and corrupt politicians to improve their career prospects and, in so doing, to degrade the cost efficiency of public projects - either directly or through their appointees. The core relevance of corruption for the optimal design of procurement has already been discussed by Søreide (2002), Compte et al. (2005), Auriol (2006), and Estache (2011) to cite just a few studies.

Our focus is on the interaction of incentives for corruption and incentives to become a politician. Early attempts to study the endogenous quality of the pool of these actors go back to Besley and Coate (1997) and Besley and Coate (1998). ${ }^{9}$ Our model relates even more closely to five more recent papers. Caselli and Morelli (2004) study the endogenous pool of politicians in the presence of heterogeneous ability and corruption. They emphasize the reputation externalities of politicians with respect to each other. Besley and Smart (2007) consider the selection of politicians with heterogeneous preference for corruption. They show that better auditing - modelled as a technology transmitting information about corruption to voters - may lead to higher corruption by giving more incentives to corrupt politicians to steal in a first term, as they know they are less likely to be reelected. Poutvaara and Takalo (2007) show that higher pay for political offices (or

\footnotetext{
${ }^{9}$ See also the survey by Besley (2005).
} 
lower campaigning costs) may raise the quality of politicians if only the least able citizens are candidate, but may lower it if the most able are already participating. Mattozzi and Merlo (2008) also predict that higher compensation may lower the quality of politicians by broadening the base of citizens it attracts, while Gagliarducci et al. (2010) predict that more able politicians are also more likely to shirk.

Our main interest is to know how institutions are and should be designed to generate the right incentives. Part of the literature has identified various ways in which voting systems can interfere ex-ante with the election of politicians. For instance, Myerson (1993) studied the impact of electoral systems on the incentives for corruption, Smart and Sturm (2013) the impact of term limits on the ability of politicians and Ferraz and Finan (2011) the impact of electoral accountability (the possibility of being reelected) on corruption in Brazilian municipalities.

Salaries have attracted the broadest interest among the determinants of the quality of politicians. The wrong salary scales or the introduction of penalties for bad politicians may reduce the pool of good politicians from which to choose. Gagliarducci and Nannicini (2013) showed for Italian municipalities that better salaries increase the quality of politicians. Ferraz and Finan (2009) obtains similar results in Brazil. The evidence is mixed, however: Kotakorpi and Poutvaara (2011) show with Finnish data that higher earnings did not necessarily lead to more qualified politicians and Hoffman and Lyons (2015) find no significant link between pay, efficiency and corruption of U.S. state legislators and governors. Peichl et al. (2013) demonstrate that the claim that politicians could earn significantly more in the private sector is not confirmed by data on German politicians. Braendle (2015) finds that large increases in politicians' wage had no effect on the education level of the pool of members of the European Parliament. In Spain, Benito et al. (2014) show that mayors who set a high salary for themselves are not more efficient. More generally, the impact of public compensation on the corruption of civil servants remains an open question. In an experimental setup, Van Veldhuizen (2013) shows that higher wages reduce the corruptibility of officials, while Foltz and Opoku-Agyemang (2015) show that an ambitious hike in the salary of public officials in Ghana actually worsened corruption.

\section{Model}

A procurement project has to be delivered. From this point forward, we do not distinguish between elected politicians and their appointees, considering both groups as "politicians." The politician is randomly chosen from a pool of citizens applying to deliver the project (we explicitly model 
campaigning and elections in Section 6.1). Two possible sources of inefficiency can lead the project to be delivered at high cost. The first is an adverse selection problem: politicians are of unobservable ability. The second is a moral hazard problem: a competent politician may be dishonest and deliver at high cost while retaining a share of the proceeds. We study the relative impact of the quality of the judicial system (monitoring whether a politician is corrupt or not) and of accounting courts (monitoring whether the project is delivered at high cost) on cost efficiency, corruption and the rate of judicial errors. This section and the next one are positive, in the sense that we take the different parameters resulting from a policy choice as given. Section 5 is normative, in the sense that we consider a social planner endogenously choosing the said parameters to maximize different objective functions.

\subsection{Politicians}

The players in the model are utility-maximizing risk-neutral citizens. A citizen is born with an ability $\theta_{i}$, drawn from a continuous distribution with density $f(\theta)$, cumulative density $F$ and support $[0,1]$. All citizens simultaneously choose whether or not to become politicians. Then, one politician is picked randomly to deliver the project. The type of each individual is private information; all the other exogenous parameters are common knowledge.

When in office, a politician discovers a state of the world $\mu \in\{l, h\}$, reflecting the possibility to deliver the project at low cost. With probability $\theta_{i}$, the state is $l$, and the politician can deliver the project at low cost, which is normalized at $c_{l}=0$. With probability $1-\theta_{i}$, the state is $h$ and the politician has no choice but to deliver the project at high cost $c_{h}>c_{l}$. This probability is exogenous and reflects the competence of a politician: being more competent means being more often in position to deliver the project at low cost.

If the state is $l$ the politician also privately observes her opportunity to engage in corruption and steal $s$, drawn from a continuous distribution with density $g(s)$, cumulative density $G$ and support $[0,1]$. The politician can then either choose not to be guilty of corruption $(n g)$ and to actually deliver the project at low $\operatorname{cost} c_{l}$, or to be guilty $(g)$ and deliver at high cost while stealing a share $s$ of the excess cost $c_{h} \cdot{ }^{10}$ A politician thus chooses above which level of $s$ (if any) to engage in corruption. An important assumption is that, ex-ante, for a given density $g(s)$, a politician who is more competent to deliver the project is also more often in the position to steal, because she is more often in position to deliver the project at low cost. We relax this assumption in Section 6.3,

\footnotetext{
${ }^{10} \mathrm{We}$ do not consider the possibility for a politician to steal less and deliver the project strictly between low and high cost. As we assume the realized cost of an honest politician to be binary, any such intermediary cost would reveal corruption with certainty in our setup and therefore never be part of an equilibrium strategy.
} 
and show that doing so removes one of the channel through which better courts may lower the quality of politicians.

The competence of a politician is also reflected in her opportunity cost of working in politics, expressed by her remuneration in office net of her outside option, $w\left(\theta_{i}\right)$. We make the assumption that $\frac{\partial w}{\partial \theta}<0$ and, in most of the analysis $\frac{\partial^{2} w}{\partial \theta^{2}}=0$, so that $\frac{\partial w}{\partial \theta}$ is the marginal increase in the opportunity cost of being in office when being more competent. This assumption drives the selection problem: a more talented citizen, being more talented both inside and outside of politics, has a higher opportunity cost by becoming a politician.

The strategy of a citizen is a double $\{E, s\}$, where $E \in\{j, n j\}$ is the decision of whether $(j)$ or $\operatorname{not}(n j)$ to join the pool of politicians, and $s \in[0,1]$ is the level above which a politician under state $l$ prefers to steal $(g)$ than to deliver a project at low cost $(n g)$. A strategy $\left\{E^{*}, s^{*}\right\}$ is an equilibrium for a citizen of type $\theta_{i}$ if $U_{\theta_{i}}\left(E^{*}, s^{*}\right) \geq U_{\theta_{i}}(E, s)$ for all $\{E, s\}$.

\subsection{The judicial system}

Once the project is delivered, two courts release an informative signal. First, the accounting court releases a signal $\omega_{a} \in\{l, h\}$ on the cost of the project (low or high). The signal is informative and correct with probability $p \in(1 / 2,1)$. Formally, for a given project, $\operatorname{Pr}\left[c_{h} \mid \omega_{a}=h\right]=\operatorname{Pr}\left[c_{l} \mid \omega_{a}=\right.$ $l]=p$ and $\operatorname{Pr}\left[c_{h} \mid \omega_{a}=l\right]=\operatorname{Pr}\left[c_{l} \mid \omega_{a}=h\right]=1-p$.

If and only if the project cost is reported as high, the judicial system releases a signal $\omega_{j} \in$ $\{c, n c\}$, correct with probability $q \in(1 / 2,1)$, on whether the politician is corrupt (c) or not $(n c)$. Formally, for a given project, $\operatorname{Pr}\left[g \mid \omega_{j}=c\right]=\operatorname{Pr}\left[n g \mid \omega_{j}=n c\right]=q$ and $\operatorname{Pr}\left[g \mid \omega_{j}=n c\right]=\operatorname{Pr}[n g \mid$ $\left.\omega_{j}=c\right]=1-q$.

The politician is convicted and receives a utility punishment of $\gamma>0$ if and only if both courts find her guilty $\left(\omega_{a}=h, \omega_{j}=c\right)$. The parameters $p$ and $q$ reflect the respective quality of the two judicial institutions and, like the punishment $\gamma$, are exogenous until Section 5. By "quality," we have in mind measures such as the extent of financial resources or autonomy of the courts, so that better courts generate fewer false positives and fewer false negatives. Better courts are not the same as more severe courts, which would decrease the number of false negatives at the cost of increasing the number of false positives. We study the latter in Section 6.2.

\subsection{Timing of the game}

To summarize, the timing is as follows: 
1. Citizens privately learn their ability $\theta_{i}$ out of a known distribution and decide whether or not to become politicians.

2. Within the pool of politicians, one is chosen randomly to be in charge of the procurement project.

3. The chosen politician privately observes whether the state of the world is $l$ or $h$.

4. Conditional on observing a signal $l$, she privately notes her ability to steal $s$ and chooses whether or not to do so.

5. The two courts release their public evaluation. The politician is given a punishment $\gamma$ if she is found to have incurred high cost $\omega_{a}=h$ and convicted of corruption $\omega_{j}=c$.

\subsection{Equilibrium strategy}

The expected utility of a citizen of type $\theta_{i}$ choosing a strategy $\left\{j, s^{*}\right\}$, to become a politician, and to steal if and only if $s \geq s^{*}$, is given by

$$
U_{\theta_{i}}\left(j, s^{*}\right)=w\left(\theta_{i}\right)-\left(1-\theta_{i}\right) \gamma p(1-q)+\theta_{i}\left(-\int_{0}^{s^{*}} \gamma(1-q)(1-p) g(s) d s+\int_{s^{*}}^{1}\left(s c_{h}-\gamma q p\right) g(s) d s\right)
$$

The utility is the sum of the following four elements. First, the remuneration net of opportunity $\operatorname{cost} w$. Second, the expected punishment when the state of the world is $h$ (with probability $1-\theta_{i}$ ), and the politician is incompetent, delivering the project at high cost without dishonesty. The politician is given a punishment $\gamma$ when the project is correctly reported by the accounting court as high cost (with probability $p$ ) and judges mistakenly find her to have been corrupt (with probability $1-q$ ). Third, when the state is $l$ (with probability $\theta$ ), for the lowest values of $s$, the politician has little to gain from corruption and delivers the project at low cost (with probability $\left.G\left(s^{*}\right) \theta_{i}\right)$. In that case, she receives a punishment $\gamma$ if both courts make a mistake, with probability $(1-q)(1-p)$. Finally, for the highest values of $s$, the politician chooses to accept corruption and steals a share $s$ of the cost difference $c_{h}$, receiving punishment $\gamma$ if both courts send a correct signal, with probability $p q$.

A citizen who plays a strategy $\{n j, s\}$ receives utility normalized to $U(n j, s)=0$ for all values of $s$, since she does not join the pool of politicians.

We want to identify the citizens for whom $U_{\theta_{i}}\left(j, s^{*}\right) \geq 0$, who constitute the equilibrium pool of politicians. For this, we must first identify $s^{*}$, the threshold value above which politicians start 
stealing.

Lemma 1 At equilibrium, a politician in a state of the world $\mu=l$ prefers to steal whenever $s \geq \hat{s}=\frac{\gamma(p+q-1)}{c_{h}}$, so that

$$
s^{*}=\left\{\begin{array}{cc}
\hat{s} & \text { iff } \hat{s} \in[0,1] \\
1 & \text { iff } \hat{s} \geq 1 .
\end{array}\right.
$$

The formal proof is in the Appendix. Conditional on entry, the probability that a politician of type $\theta_{i}$ accepts a bribe is given by

$$
S\left(\theta_{i}\right)=\theta_{i}\left(1-G\left(s^{*}\right)\right)
$$

so that $\frac{\partial S}{\partial \theta}>0$. The fact that in a given set of politicians the more talented steal more is a direct consequence of the fact that they have more opportunity to do so. However, more talented politicians also deliver more often at low cost so that, unless a social planner is interested in fighting corruption as a matter of principle, it should always prefer, all other things held equal, higher quality politicians.

In order to obtain closed form solutions it is useful to simplify the problem by assuming that $w(\theta)$ is linear, with the remuneration from politics net of opportunity cost of the least able citizen $w(0)=w_{o}$ and the marginal increase in the opportunity cost of being in office for higher types $\frac{\partial w}{\partial \theta}=-\bar{w}$. For a citizen of type $\theta_{i}$ the decision of whether to enter the pool of politicians $U_{\theta_{i}} \geq 0$ is derived directly from (1),

$$
\theta_{i}\left(\gamma(1-q)(2 p-1)+\int_{s^{*}}^{1} c_{h}\left(s-s^{*}\right) g(s) d s-\bar{w}\right) \geq \gamma(1-q) p-w_{0}
$$

The impact of competence on willingness to enter the pool of active politicians is ambiguous. On the one hand, being of greater competence decreases the incentives to enter, as more able politicians have a higher opportunity cost. On the other hand, it increases the incentives to enter, as one has a lower risk of being convicted while behaving honestly, and more opportunities to be dishonest. While judicial and accounting courts have comparable effects on individual corruption, they have a different impact on judicial errors. An increase in the quality of judicial courts $q$ is of more benefit to the less competent, who tend not to be guilty of corruption, while an increase in $p$ may yield greater benefit to either type, as it decreases their probability of being falsely convicted when the probability of producing at low cost is higher, but it also forgoes the benefits from corruption. 
We can define the marginal benefit and the marginal cost of being a politician of a higher type. The marginal benefit is given by

$$
M B_{\theta}=\gamma(1-q)(2 p-1)+\int_{s^{*}}^{1} c_{h}\left(s-s^{*}\right) g(s) d s
$$

The impact of the quality of the judicial system on the marginal benefit of being a high type is always negative, $\frac{\partial M B_{\theta}}{\partial q}=-\gamma\left((2 p-1)-\left(1-G\left(s^{*}\right)\right) g\left(s^{*}\right)\right)<0$. Indeed, the derivative of the first term of equation (4) with respect to $q$ is negative, and by Lemma 1 we know that $\frac{\partial s^{*}}{\partial q}=\frac{\gamma}{c_{h}}>0$. The impact of the quality of the accounting court $\frac{\partial M B_{\theta}}{\partial p}=\gamma\left(2(1-q)-\left(1-G\left(s^{*}\right)\right) g\left(s^{*}\right)\right)$ is ambiguous however, as the derivative of the first term of equation (4) with respect to $p$ is positive whereas the derivative with respect to the second term is negative.

The marginal cost of being a politician of higher type is given by the increase in the opportunity cost of being in office

$$
M C_{\theta}=\bar{w},
$$

and is a constant as we have assumed $w(\theta)$ to be linear.

Finally, using the linear form of $w(\theta)$, the payoff to a politician in office of the lowest possible ability $\theta_{i}=0$ can be written as

$$
U_{0}(j)=w_{0}-\gamma(1-q) p
$$

with $\frac{\partial U_{0}(j)}{\partial q}>0$ and $\frac{\partial U_{0}(j)}{\partial p}<0$. The politician with the lowest possible ability is never corrupt, as she never has the opportunity to produce at a low cost. For that reason, judges of higher quality always benefit her. But because she always produces at a high cost, accounting courts of higher quality always decrease her payoff from holding when in office.

For the entire analysis, we study the problem in terms of $U_{0}(j), M B_{\theta}$ and $M C_{\theta}$, so that the payoff of a citizen of type $\theta_{i}$ joining politics is

$$
U_{\theta_{i}}\left(j, s^{*}\right)=U_{0}(j)+\theta_{i}\left(M B_{\theta}-M C_{\theta}\right) .
$$

Using (7) we can then define the indifferent type $\hat{\theta}$ as the solution to the following equality:

$$
\hat{\theta}=\frac{-U_{0}(j)}{M B_{\theta}-M C_{\theta}} .
$$


We can now formally present the equilibrium strategy of citizens.

Proposition 1 In equilibrium, either only the most able or the least able citizens enter politics. The equilibrium strategy of a given citizen is a pair $\left\{E, s^{*}\right\}$. The corruption threshold $s^{*}$ is defined in Lemma 1. If $M B_{\theta}>M C_{\theta}, E=j$ for all $\theta_{i} \geq \theta^{-}=\max \{\hat{\theta}, 0\}$. If $M B_{\theta}<M C_{\theta}, E=j$ for all $\theta_{i} \leq \theta^{+}=\min \{\hat{\theta}, 1\}$.

The proof is presented in the Appendix. Depending on whether the marginal benefit of being of a higher type is greater than the marginal cost, the pool of politicians consists entirely of either only the most able or the least able citizens, but never of disjoint subsets of $[0,1]$. The game can also lead to corner solutions where either all or no citizens enter. When $M B_{\theta} \rightarrow M C_{\theta}$, the denominator of (8) goes to zero. This implies that for $M B_{\theta}>M C_{\theta}$ the condition goes to $\theta \geq \infty$ if and only if $U_{0}(j)<0$ (no citizens enter) and $\theta \geq-\infty$ if and only if $U_{0}(j)>0$ (all citizens enter). Similarly, for $M B_{\theta}<M C_{\theta}$ the condition goes to $\theta \leq-\infty$ if and only if $U_{0}(j)<0$ (no citizens enter) and $\theta \leq \infty$ if and only if $U_{0}(j)>0$ (all citizens enter). This implies a continuity in the equilibrium quality of the pool of politicians because, depending on the value of $U_{0}(j)$ at this point, either all or no citizens choose to enter politics around the values at which $M B_{\theta}=M C_{\theta}$. Note that the assumption of opportunity cost linear with ability is critical for the result that only one threshold value of $\theta$ determines who joins the pool of politicians. More general functions could lead to disconnected intervals of $\theta_{i}$ entering politics. While this is clearly a limitation of our approach, the marginal impact of the various parameters on each politician is not affected by this assumption.

In the next section, we study how the equilibrium is affected by the quality of the two types of courts.

\section{Analysis}

We consider first the impact of the quality of the judicial and accounting courts on the quality of the pool of politicians. We then examine the impact on cost efficiency and the aggregate level of corruption.

\subsection{The effect of court quality on the pool of politicians}

The following proposition characterizes the effect of the quality of judges on the competence of active politicians. 
Proposition 2 When only the most able citizens enter politics $\left(M B_{\theta}>M C_{\theta}\right)$, the average ability of the pool of politicians drops when the quality of the signal sent by judges $q$ rises if and only if $\hat{\theta} \leq-\frac{\partial U_{0}(j) / \partial q}{\partial M B_{\theta} / \partial q}=\frac{p}{(2 p-1)+g\left(s^{*}\right)\left(1-G\left(s^{*}\right)\right)}$. When only the least able citizens enter politics $\left(M B_{\theta}<\right.$ $\left.M C_{\theta}\right)$, the average ability of politicians decreases with $q$ if and only if $\hat{\boldsymbol{\theta}} \geq-\frac{\partial U_{0}(j) / \partial q}{\partial M B_{\theta} / \partial q}$.

The formal proof is presented in the Appendix. The two cases are not exogenous: because $\frac{\partial M B_{\theta}}{\partial q}<0$ and $\frac{\partial M C_{\theta}}{\partial q}=0$, changes in the quality of judges $q$ affect whether the most $\left(M B_{\theta}>M C_{\theta}\right)$ or the least $\left(M B_{\theta}<M C_{\theta}\right)$ able citizens enter politics. Regardless of the case, a change in $q$ affects politicians in two ways. The first derives from the fact that $\frac{\partial M B_{\theta}}{\partial q}<0$ and is a selection effect: better quality signals sent by judicial courts decrease the advantage of being a more able politician, as the relative advantage derives from avoiding more judicial errors while innocent and from being able to steal more often. This effect decreases the utility of all politicians, but it particularly affects the most able among them. The second effect derives from $\frac{\partial U_{0}}{\partial q}>0$ and is an entry effect: the presence of judges of higher quality makes it safer overall to be a politician (stealing is always a choice). Assume for a moment that $M B_{\theta}>M C_{\theta}$. If the first effect predominates for the "threshold" politician indifferent between entering or not, this politician is worse off when $q$ increases. This implies that fewer citizens enter the pool of politicians and that those politicians are of higher quality. If the second effect predominates, the "threshold" politician is made better off by the higher quality of judges: hence more politicians (of lesser ability) enter. All other things held equal, the first effect is more likely to predominate if the threshold politician is of a high type (as she has more to lose). Assuming now that $M B_{\theta}<M C_{\theta}$, if the first effect predominates, fewer citizens enter politics and the average quality decreases because only the least able citizens enter, while the opposite is true if the second effect predominates.

It is possible to rewrite the condition in Proposition 2 to show that the threshold politician is made better off by an increase in $q$ if and only if

$$
(1-\hat{\theta}) p+\hat{\theta}(1-p) \geq \hat{\theta}\left(1-G\left(s^{*}\right)\right) g\left(s^{*}\right)
$$

The left-hand side decreases with the threshold politician's ability $\hat{\theta}$ and represents the benefits of the possibility of being found innocent more often when $q$ increases. As politicians of greater ability are less often in state $h$, where the probability of being convicted while non-corrupt is higher, they benefit less from this effect. The right-hand side is the loss of the benefits of corruption. As the higher types benefit more often from bribes in equilibrium, the negative impact on them is higher. Note that without corruption $\left(s^{*} \rightarrow 1\right)$ an increase in $q$ always benefits everyone. It is only 


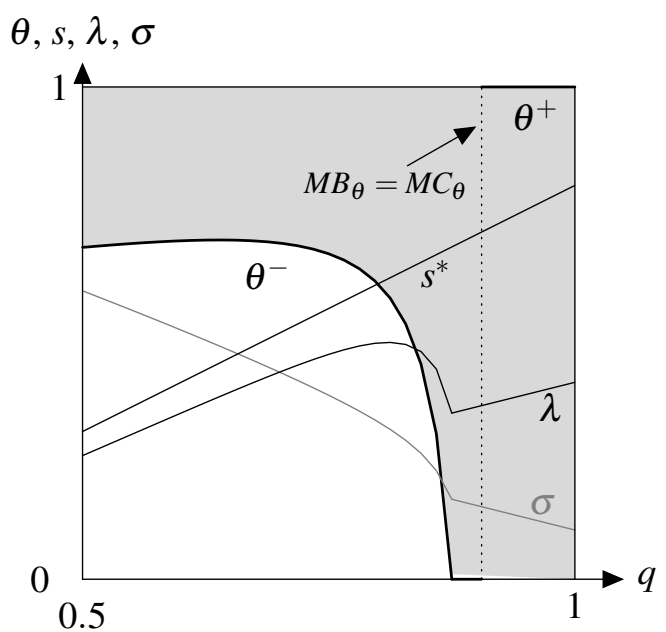

Figure 1.A: $\gamma=5, p=0.8, \bar{w}=0.5, w_{0}=0.5$ $\theta, s, \lambda, \sigma$

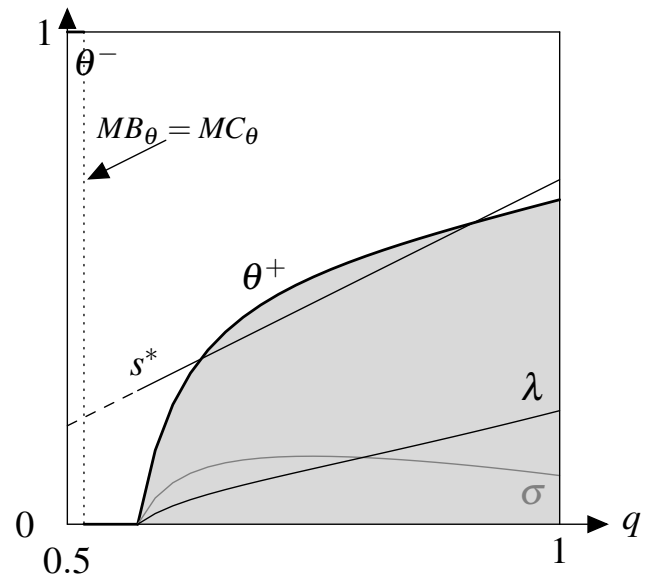

Figure 1.B: $\gamma=2, p=0.7, \bar{w}=1, w_{0}=0.6$

Figure 1: Comparative statics on the quality of the judicial system $q$, with $c_{h}=\gamma$ and $G(s)=s$. The share of corruption opportunities refused is $s^{*}, \sigma$ the share of projects affected by corruption, $\lambda$ the share of projects delivered at low cost, $\theta^{-}$the marginal citizen when $M B_{\theta}>M C_{\theta}, \theta^{+}$the marginal citizen when $M B_{\theta}<M C_{\theta}$.

because it decreases the benefits from corruption that some more able politicians may be worse of when the quality of the signal sent by judges increases.

We illustrate the effect of the quality of judicial courts $q$ in Figure 1, in two different contexts. ${ }^{11}$ The gray area represents the range of ability of the politicians at equilibrium. Figure 1.A aims at representing a country with relatively favourable conditions: a relatively narrow dispersion of the opportunity cost of being in office $\bar{w}$, high punishment when convicted $\gamma$, and a relatively competent accounting court $p$. From the left border to the mark line, $M B_{\theta}>M C_{\theta}$ so that all citizens of ability greater than $\theta^{-}$enter politics. To the right of the mark line, $M B_{\theta}<M C_{\theta}$, and only politicians with ability lower than $\theta^{+}$enter (remember that $M B_{\theta}$ always decreases with $q$ ). For the lowest values of $q$, corruption is relatively widespread when the state of the world is $l$ (low $s^{*}$ ), and the "threshold" politician $\hat{\theta}$ is of relatively high ability. Hence, when $q$ increases the threshold politician is made slightly worse off, so that the marginally less able citizens leave the pool of politicians. For intermediate values of $q$, politics becomes more and more attractive for the least able citizens, as they are less likely to be the subject of a judicial error, up to the point where all citizens join the pool of politicians.

Figure 1.B corresponds to much less favourable conditions: a higher dispersion of opportunity costs of being in office, lower punishment when convicted, and a relatively less competent accounting court. For the lowest values of $q$, no citizen wants to enter, as the risk of being mistak-

\footnotetext{
${ }^{11}$ For all figures, we use a uniform distribution for $s$, so that if $\hat{s} \leq 1, \hat{\theta}=-\frac{2 c_{h}\left(w_{0}+\gamma p(q-1)\right)}{c_{h}^{2}-2 c_{h}(\gamma p(2 q-1)+\bar{w})+\gamma^{2}(p+q-1)^{2}}$ and if $\hat{s}>1, \hat{\theta}=\frac{w_{0}+\gamma p(q-1)}{\gamma(2 p-1)(q-1)+\bar{w}}$.
} 
enly sanctioned is too high for everyone. When $q$ increases, some citizens of low ability begin to enter, and the quality of the pool of politicians increases in inverse proportion to the risk of being erroneously convicted, while corruption falls.

Finally, both figures point to a role of the marginal politician that is reminiscent of Poutvaara and Takalo (2007). When only the most able citizens enter politics, making the profession more financially attractive decreases the quality of politicians. When only the least able enter, making politics more attractive increases the quality of politicians.

Proposition 3 When only the most able citizens enter politics $\left(M B_{\theta}>M C_{\theta}\right)$, the average ability of the pool of politicians decreases as the quality of the signal sent by the accounting court $p$ increases if and only if $\hat{\theta} \leq-\frac{\partial U_{0}(j) / \partial p}{\partial M B_{\theta} / \partial p}=\frac{1-q}{(1-q)-g\left(s^{*}\right)\left(1-G\left(s^{*}\right)\right)}$. When only the least able enter $\left(M B_{\theta}<M C_{\theta}\right)$, the average ability of politicians decreases with $p$ if and only if $\hat{\boldsymbol{\theta}} \geq-\frac{\partial U_{\theta}(j) / \partial p}{\partial M B_{\theta} / \partial p}$.

The proof is similar to that of Proposition 2 in the Appendix. Politicians are affected in two ways as the quality of the signal sent by the accounting court $p$ increases. The first effect is a selection effect, that may either be positive for all politicians, but relatively more so for the most able, or negative for all politicians, but relatively less so for the least able. As better accounting courts decrease corruption, and as politicians of higher ability accept more bribes, their utility loss from lower corruption grows with $p$. However, a higher $p$ makes it more likely that an honest politician of low ability will be reported as having incurred a high cost, and less likely that an honest politician of high ability will suffer the same fate. The second effect, an entry effect, is negative for all politicians, as the probability of being caught when delivering at high cost is higher.

When $M B_{\theta}>M C_{\theta}$ : If the sum of the two effects is negative for the "threshold" politician indifferent between entering or not, this politician becomes worse off as $p$ increases. Because when $M B_{\theta}>M C_{\theta}$ only the most able citizens become politicians, the pool of politicians is smaller and of higher quality. This can be the case even if the first effect is positive but not large enough to counterbalance the second. Similarly, when $M B_{\theta}<M C_{\theta}$, as only the least able citizens enter politics, if the payoff to the threshold politician decreases, the average quality of the pool decreases.

It is possible to rewrite the condition in Proposition 3 to show that the threshold politician is made better off by an increase in the competence of accounting courts $p$ if and only if

$$
(1-q)(2 \hat{\theta}-1) \geq \hat{\theta} g\left(s^{*}\right)\left(1-G\left(s^{*}\right)\right) .
$$


The left-hand side is positive for the most able politicians $\theta \geq \frac{1}{2}$ and represents the benefits of a greater likelihood of being found innocent when the state of the world is $l$ minus the cost of a greater likelihood of being found guilty when the state of the world is $h$. As politicians of greater ability are more often in state $l$, they benefit more from this effect. The right-hand side is the loss from the benefits of corruption, identical to the loss created by an increase in the quality of judges $q$. As the more able politicians benefit more often from bribes in equilibrium, the negative impact on them is higher. Without corruption $\left(s^{*} \rightarrow 1\right)$, an increase in $p$ always benefits the most able half of the politicians and hurts the others. Because an increase in $p$ also decreases the benefits from corruption, the actual level of $\theta$ at which politicians start benefiting from an increase in $p$ is higher. All politicians can even be made worse off if $\frac{\partial M B_{\theta}}{\partial p} \leq 0$.

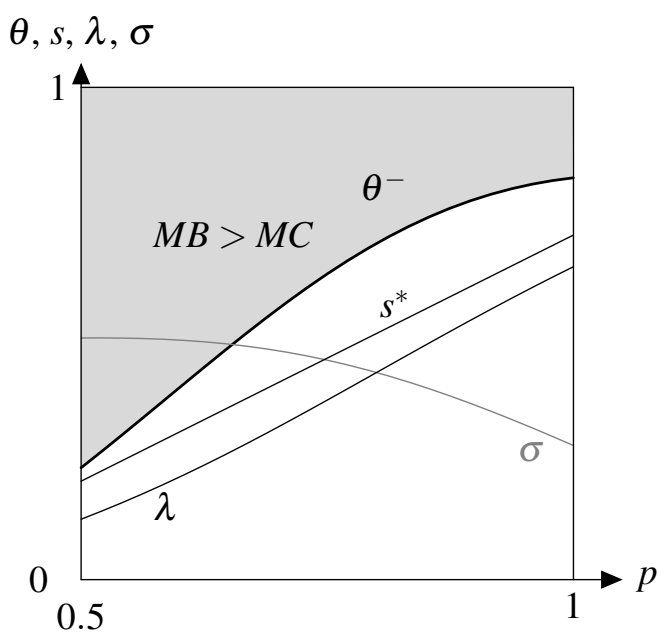

Figure 2.A: $\gamma=5, \bar{w}=0.5, w_{0}=0.3$

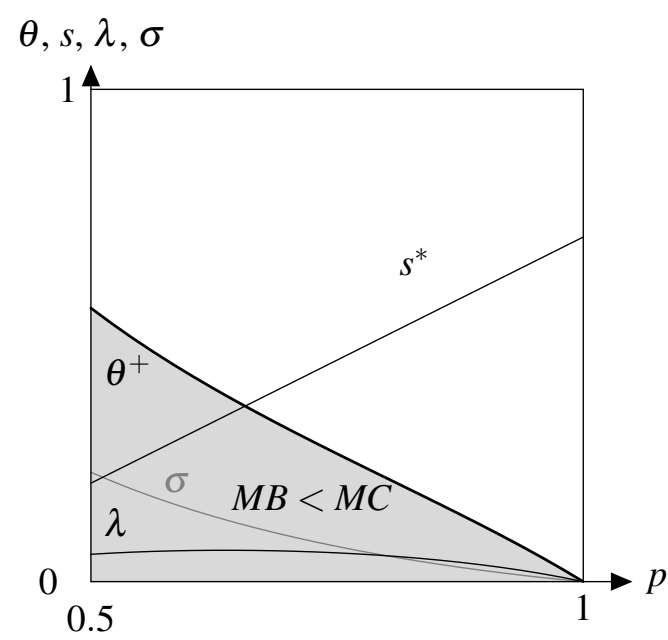

Figure 2.B: $\gamma=2, \bar{w}=1, w_{0}=0.6$

Figure 2: Comparative statics on the quality of the accounting courts $p$, for $q=0.7, \gamma=c_{h}$ and $G(s)=s$. The share of corruption opportunities refused is $s^{*}, \sigma$ the share of projects affected by corruption, $\lambda$ the share of projects delivered at low cost, $\theta^{-}$the marginal citizen when $M B_{\theta}>M C_{\theta}, \theta^{+}$the marginal citizen when $M B_{\theta}<M C_{\theta}$.

We illustrate the two effects in Figure 2. The gray area represents the range of ability of the politicians entering the pool at equilibrium. Figure 2.A corresponds to what would intuitively be favourable conditions: low dispersion of opportunity cost and severe punishment when convicted. Hence, only the most able citizens choose to enter politics, $M B_{\theta}>M C_{\theta}$. For the lowest values of $p$, the risk of being reported for having incurred high cost when in state $h$ is not very high, so that a large share of the least able citizens chooses to enter politics. Moreover, corruption is relatively widespread. As $p$ increases, corruption decreases, and the average ability of politicians begin to rise as the risk to those of lower ability of being wrongfully convicted for high costs rises. Hence, a higher $p$ both increases the average ability of politicians and decreases corruption. 
Figure 2.B could represent a country facing what would intuitively be described as less favourable conditions, where the marginal increase in the opportunity cost of being in office $\bar{w}$ is higher, and punishments for corruption $\gamma$ are less severe. In this case, only the least able citizens enter politics, $M B_{\theta}<M C_{\theta}$. Both the potential benefits $c_{h}$ from corruption and the costs $\gamma$ of being convicted are lower. For the lowest values of $p$, corruption is high, and the risk of being reported for high costs while accepting bribes remains sufficiently low for some relatively able citizens to enter. As $p$ increases, the possibility of benefiting from bribes decreases, so that the most able citizens cease to join the pool of politicians. Hence, raising $p$ decreases corruption, but it also decreases the average quality of the politicians.

\subsection{The impact of court quality on procurement performance}

\section{a. Cost efficiency}

It is now possible to analyse the effect of the quality of the judicial and accounting courts on the probability that a project is delivered at a low cost. It is useful to define the expected ability of a politician as $\bar{\theta}$, with

$$
\bar{\theta}= \begin{cases}\frac{\int_{\theta^{-}}^{1} \theta f(\theta) d \theta}{1-F\left(\theta^{-}\right)} & \text {for } M B_{\theta}>M C_{\theta} \\ \frac{\int_{0}^{\theta^{+}} \theta f(\theta) d \theta}{F\left(\theta^{+}\right)} & \text {for } M B_{\theta}<M C_{\theta} .\end{cases}
$$

The equilibrium probability that a project is delivered at low cost is

$$
\lambda=G\left(s^{*}\right) \bar{\theta}
$$

The probability that a project is delivered at low cost is equal to the probability that a politician does not steal when in state $l, G\left(s^{*}\right)$, multiplied by the expected ability of a politician $\bar{\theta}$, which is equal to her probability of being in state $l$. The expected ability of a politician is derived directly from Proposition 1.

Proposition 4 Courts of higher quality marginally increase the cost efficiency of procurement projects if their possibly negative effect on the average ability of the pool of politicians, does not outweigh their contribution to deterring corruption,

$$
-\frac{\partial \bar{\theta}}{\partial i} G\left(s^{*}\right) \leq \frac{\partial s^{*}}{\partial i} g\left(s^{*}\right) \bar{\theta}
$$

with $i \in\{q, p\}$. 
Proof. The proof directly follows from deriving $\frac{\partial \lambda}{\partial q}$ and $\frac{\partial \lambda}{\partial p}$, with $\lambda$ defined in (11)

The left-hand side represents the loss of cost efficiency for a given level of corruption when the pool of candidates is modified by the quality of the court. It is given by $\frac{\partial \bar{\theta}}{\partial i}$, the impact of the quality of the court $i \in\{q, p\}$ on the average ability of a politician, multiplied by $G\left(s^{*}\right)$, the probability that a given politician in state $l$ refuses a bribe (with a minus sign).

The right-hand side represents the gain of cost efficiency for a given pool of politicians when the rate of corruption $s^{*}$ is modified by the quality of the court. There may be a tradeoff between the quality of the pool of politicians and the level of corruption. In particular, if higher quality of the judicial or accounting court lowers the quality of the pool of politicians, the cost efficiency of the projects may decrease even though the probability that a given politician will be corrupt is lessened. The probability that a project will be delivered at low cost $\lambda$ is represented in both Figures 1 and 2, with $F(\theta)=\theta$. It is easy to see that the average cost efficiency of the projects delivered always increases with $q$ or $p$ when this variable raises the average quality of the pool of politicians, but that otherwise it has an ambiguous effect.

Increasing the quality of a court is harmful if it decreases the average ability of politicians without exerting a sufficiently powerful effect on corruption. This state of affairs may occur because the share of accepted bribes is already very small, or because corruption is not the most important problem (if the average ability of politicians is very low). The share of accepted bribes unambiguously decreases with $q, p$ and $\gamma$. Average ability is low if politics is attractive to everyone (high wages $w_{0}$, low punishment $\gamma$ ) or if it is attractive only to the least able (high marginal opportunity cost $\bar{w}$, good judges $q$ ). In Figure 1, cost efficiency decreases with $q$ if $q$ and $p$ are sufficiently high for corruption to be small and if $\bar{w}$ is sufficiently low for the most able to enter. In Figure 2 it decreases with $p$ if $p$ and $q$ are sufficiently high for corruption to be small, and if $\bar{w}$ is sufficiently high that only the least able choose to enter politics.

\section{b. Aggregate level of corruption}

It is also possible to study the rate of corruption $\sigma$, which is defined as the share of projects for which a politician has accepted a bribe. The equilibrium probability that a project has been subject to corruption is given by

$$
\sigma=\bar{\theta}\left(1-G\left(s^{*}\right)\right)
$$


The probability that a project has been subject to corruption is equal to the probability that a politician steals when in state $l, 1-G\left(s^{*}\right)$, multiplied by the expected ability of the politician, which is equal to her probability of being in state $l$. The expected ability of a politician is derived directly from Proposition 1.

Proposition 5 Courts of higher quality marginally decrease the share of procurement projects subject to corruption if their possibly negative effect on the average ability of the pool of politicians does not outweigh their contribution to deterring corruption,

$$
\frac{\partial \bar{\theta}}{\partial i}\left(1-G\left(s^{*}\right)\right) \leq \frac{\partial s^{*}}{\partial i} g\left(s^{*}\right) \bar{\theta}
$$

with $i \in\{q, p\}$.

Proof. The proof directly follows from deriving $\frac{\partial \sigma}{\partial q}$ and $\frac{\partial \sigma}{\partial p}$, with $\sigma$ defined in (13)

The right-hand side of (14) is the marginal effect of the quality of a court on the rate of corruption of each politician $s^{*}$ for a given average ability $\bar{\theta}$. The left-hand side is the marginal effect on the quality of the pool of politicians for a given $s^{*}$. If courts of higher quality improve the average ability of politicians, this may therefore have the indirect effect of increasing corruption. In that case, courts of lower quality may decrease corruption simply because politicians are less often able to steal. The probability that a project is subject to corruption $\sigma$ is represented in both Figure 1 and 2, with $F(\theta)=\theta$. It is easy to see that the cases in which corruption decreases the most drastically are those in which the quality of politicians also decreases, which raises the expected cost of a project. Since only projects carried out in state $l$ can be subject to corruption, it always holds that the sum of $\lambda$ and $\sigma$ is equal to the average ability of those who join the pool of politicians $\bar{\theta}$.

A typical case corresponds to part of the right-hand side of Figure 1. For the lowest values of $q$, the very least able citizens enter politics and corruption makes up a large share of politicians' income (low $p, q$, high $\gamma$ and $\bar{w}$ ). Hence, better judicial courts increase the average ability of politicians but also increase corruption. This is the only one of our examples where the so-called tradeoff hypothesis between corruption and ability holds. While we make the assumption that, in a given environment, the most able politicians are more often subject to corruption, we find that there is no general tradeoff. If the corruption deterrence effect dominates the selection effects, better courts decrease both corruption and incompetence. 


\section{c. Judicial errors}

Finally, the share of judicial errors can be easily characterized as the expected probability that a politician is punished without having accepted a bribe. The equilibrium probability that a politician is convicted without having engaged in corruption is given by

$$
\phi=(1-q)((1-p) \lambda+p(1-\lambda-\sigma))
$$

One form of judicial error affects politicians who deliver projects at low cost $(\lambda)$, are wrongfully reported as having incurred high cost $(1-p)$, and are then wrongfully convicted $(1-q)$. A second form involves politicians who deliver at high cost without being corrupt, $(1-\lambda-\sigma)$, are correctly reported as having incurred high costs $(p)$ and are then wrongfully convicted $(1-q)$. When the quality of the judicial courts increases, it has the direct effect of both decreasing the probability of a judicial error in a given case and decreasing the probability that a given politician will accept bribes. However, if it also decreases the quality of the pool of politicians it may actually increase the share of judicial errors by increasing the number of cases in which honest politicians are investigated for having incurred high cost (while in state $h$ ). When the quality of the accounting courts increases, it has the direct effects of decreasing corruption, increasing the probability that a politician in state $h$ is reported for high cost and decreasing the probability that a politician in state $l$ is so reported. Hence, the sum of the direct effects may actually be to increase the probability of a judicial error. This effect can be either exacerbated or mitigated by the indirect effect of $p$ on the quality of the pool of politicians.

\section{Policy}

The previous sections were positive: We discussed the equilibrium and comparative statics of the game, while taking as exogenous the parameters on which a social planner may have an influence: the quality of judges $q$, the quality of accounting courts $p$, politicians' remuneration $w_{0}$ and punishment level $\gamma$. In this section, we consider the normative question of what these values should be depending on the objective of the social planner. We set up an initial stage of the game, where a government chooses the parameters in order to maximize an objective function $V$ given the expected strategy of citizens,

$$
\max _{q, p, w_{0}, \gamma} V(\lambda, \sigma, \phi)
$$


We assume that a social planner may have an interest in three different objectives: maximizing the share of low cost projects delivered $\frac{\partial V}{\partial \lambda} \geq 0$, minimizing the share of projects subject to corruption $\frac{\partial V}{\partial \sigma} \leq 0$, and minimizing the number of judicial errors in which an innocent politician is convicted $\frac{\partial V}{\partial \phi} \leq 0.12$ We start by discussing the marginal impact of each instrument by narrowing the analysis of the share of projects delivered at low $\operatorname{costs} \lambda$, and then study the characteristics of a first-best policy for a general function $V$. A first-best policy based on the combination of the two courts described herein is obviously not the only one that might be conceived. The first-best can in general be achieved by any policy that makes public officials residual claimants of the procurement processes they manage.

It is essential to keep in mind, as suggested by Bandiera et al. (2009), that real world constraints such as limited liability may render the first-best unfeasible. Moreover, making politicians residual claimants would imply a perfect understanding of what a low-cost project is, something that we argue is subject to the imperfect evaluations of accounting courts.

\subsection{Impact of marginal policy changes on the share of projects delivered at low cost}

In this subsection, we focus on the marginal benefit to a social planner of modifying the value of a single parameter. While it is possible to perform the exercise for each of the parameters studied in the previous subsections, the most obvious candidate is the share of projects that a social planner can expect to deliver at low cost $\lambda$.

The most direct instrument to influence cost-efficiency is the remuneration of politicians, given by $w_{0}$. As $\bar{w}$ is constant, increasing $w_{0}$ increases the remuneration of all politicians by the same amount. Using the results from the previous sections, it is possible to show that

$$
\frac{\partial \hat{\theta}}{\partial w_{0}}=-\frac{1}{M B_{\theta}-M C_{\theta}},
$$

and $\frac{\partial s^{*}}{\partial w_{0}}=0$. Hence $\frac{\partial \lambda}{\partial w_{o}} \geq 0$ if and only if $M B_{\theta}<M C_{\theta}$. It is only if the least able citizens choose to join the pool of politicians that increasing politicians' salaries has a positive effect. Otherwise, increasing salaries actually decreases the quality of the projects delivered by decreasing the average ability of politicians. This result may help explain the conflicting evidence on the impact of remuneration on the quality of politicians. For instance, in a country like Sweden, where only the most able citizens become politicians (Dal Bó et al., 2017), higher wages would only attract more politicians and decrease their average ability.

\footnotetext{
${ }^{12}$ For instance, Di Tella and Rotemberg (2016) argue that citizens may prefer politicians with lesser ability because they see corruption as a betrayal, more problematic that simple incompetence.
} 
The impact of the level of punishment $\gamma$ on the expected cost efficiency of projects is ambiguous because its impact on the selection of politicians is ambiguous. The impact on $M B_{\theta}-M C_{\theta}$ is

$$
\frac{\partial M B_{\theta}}{\partial \gamma}=(1-q)(2 p-1)-g\left(s^{*}\right)\left(1-G\left(s^{*}\right)\right)(p+q-1) .
$$

The first part is positive, as the more able politicians suffer relatively less from the higher cost of being convicted. The second part is negative, as the loss from taking fewer bribes affects the most able politicians disproportionately. The impact on $U_{0}$ is clearly negative, $\frac{\partial U_{0}}{\partial \gamma}=-(1-q) p$, and so is the impact on the payoff to any type of politician. Hence, the direct effect of an increase in $\gamma$ is clearly beneficial when only the most able enter $M B_{\theta}>M C_{\theta}$, as it makes it possible to target the best politicians and deter corruption, provided at least some citizens still want to enter the pool of politicians. When the least able enter, increasing the level of punishment $\gamma$ is beneficial only if the impact on corruption outweighs the selection effect.

Finally, $p$ and $q$ have been largely studied in the previous subsections. It is easy to show that $\frac{\partial \lambda}{\partial q} \geq 0$ when

$$
g\left(s^{*}\right) \frac{\gamma}{c_{h}} \bar{\theta} \geq-\frac{\partial \bar{\theta}}{\partial q} G\left(s^{*}\right)
$$

This inequality is always satisfied when $\frac{\partial \bar{\theta}}{\partial q} \geq 0$, as increasing the quality of judges decreases both corruption and incompetence. A social planner willing to decrease the share of projects delivered at low cost might do so by marginally increasing the quality of the judicial system provided the benefits from deterring corruption are not offset by attracting less able politicians. As shown in Proposition 2 this is often the case when few people are willing to enter politics, as increasing the quality of $q$ can have opposite effects on the average ability of politicians.

Similarly, $\frac{\partial \lambda}{\partial p} \geq 0$ when $g\left(s^{*}\right) \frac{\gamma}{c_{h}} \bar{\theta} \geq-\frac{\partial \bar{\theta}}{\partial p} G\left(s^{*}\right)$. As shown in Proposition 3, increasing the quality of the accounting courts is beneficial when the most able politicians enter $\left(M B_{\theta}>M C_{\theta}\right)$ and corruption is high, and detrimental when corruption is lower and the least able citizens enter politics $\left(M B_{\theta}<M C_{\theta}\right)$.

\subsection{First-best}

We show in the previous section that any of the partial solutions can lead to possibly perverse social outcomes. This section shows that to maximize any welfare function $V$ as described in (16), 
an optimal policy must fulfill three conditions. First, a condition on the absence of corruption, so that $s^{*} \geq 1$. This implies that the level of punishment should be sufficiently high,

$$
\gamma \geq \frac{c_{h}}{p+q-1}
$$

This condition is also sufficient to ensure $\sigma=0$. Second, a condition that ensures that only the most able citizens enter politics, this is $M B_{\theta} \geq M C_{\theta}$. Assuming condition (20) is fulfilled, this means that the quality of the accounting court should be sufficiently high, and the quality of the judicial courts sufficiently low,

$$
(1-q)(2 p-1) \geq \frac{\bar{w}}{\gamma}
$$

If conditions (20) and (21) are satisfied, $w_{0}$ should be the lowest value that satisfies $u(1) \geq 0$,

$$
w_{0}=\gamma(1-q)(1-p)+\bar{w} .
$$

The last two conditions ensure that only the most able citizens enter politics. Hence, as there is no corruption (by the first condition), all projects are delivered at low cost $\lambda=0$. Finally, to ensure the absence of judicial errors, it should be the case that at either $p$ or $q$ is equal to 1 or that both are. As it is impossible to fulfill condition (21) with $q=1, \bar{w}>0$ and a finite value of $\gamma$, the four conditions to be met simultaneously are $p=1, \gamma \geq \frac{c_{h}}{q}, q \leq 1-\frac{\bar{w}}{\gamma}$ and $w_{0}=\bar{w}$.

An ideal policy that simultaneously fulfills these three conditions always exists and is not unique. The following proposition offers an example.

Proposition 6 There exists a socially optimal policy where only the most able citizens $\theta=1$ enter politics, there is no corruption $(\sigma=0, \lambda=1)$, and no one is convicted if innocent $(\phi=0)$. An example of optimal policy is $p=1, q=\frac{1}{2}, \gamma>\max \left\{2 c_{h}, 2 \bar{w}\right\}$ and $w_{0}=\bar{w}$.

The formal proof is in the Appendix. In the policy presented in Proposition 6, the accounting court is able to perfectly screen the high-cost projects, and the politicians delivering at high cost receive a sufficiently high punishment to deter corruption. The judges are replaced by a random punishment of the high-cost projects (as $q=\frac{1}{2}$ ) that punishes indistinguishably the least able and the corrupt, which serves to deter entry of the least able. Finally, the salary paid to officeholders is sufficiently high to attract the most able politicians even without the benefits of corruption. It would be possible to attain the same outcome by increasing the quality of the judicial system $q$, the 
level of punishment $\gamma$ and the remuneration of the politicians $w_{0}$. As a general principle, all optimal solutions imply a sufficiently high quality of the accounting court, a sufficiently low quality of the judicial court, a sufficiently high level of punishment and a level of wages high enough to attract the most able politicians but not too high, in order to avoid attracting less able ones.

In some sense, this first best is an application to our setup of a simple incentive contract, in which the politician is made a residual claimant of the procurement project (so that greater ability is an advantage), and the participation constraint is binding for the most able citizens only. This first best thus relies on the unlikely assumption that politicians are not subject to limited liability and are risk neutral. As implied by Bandiera et al. (2009), this assumption may be sufficient to question the feasibility of this first best.

\section{Robustness checks}

This section returns to some of the assumptions of the model. First we assess the relevance of considering the possibility of campaign costs when voters screen the ability of politicians. Second, we study asymmetric errors in courts' assessments by permitting a change in the severity of the courts for a given assessment quality. Third, we relax the assumption that more able politicians are also more able at extracting rents from corruption. Fourth, we relax the assumption of homogeneity in the preferences for corruption across politicians. We present here the main results from these extensions, and provide the full development in the online Appendix.

\subsection{Campaign costs and voters' ability to screen politicians}

In this subsection, we extend the setup to explicitly model elections, following the citizen-candidate model used in Osborne and Slivinski (1996), Besley and Coate (1997), Caselli and Morelli (2004) and Poutvaara and Takalo (2007).

In the first stage, citizens simultaneously decides whether or not to become candidate. In our notation, this decision is captured by the strategy $E \in\{j, n j\}$, and a citizen playing $j$ is a "candidate." We also add to our initial setup that campaigning has a fixed cost. In the second stage, voters elect a share of the candidates, using a common imperfect observable signal of their ability. In the traditional citizen-candidate models politicians are of discrete types. As we work with a continuum of types and want to stick as much as possible to the traditional model, we assume voters observe a signal $\theta_{a} \in\{a, \bar{a}\}$, denoting respectively high $(a)$ or low $(\bar{a})$ ability. We further assume that the probability of being observed as a high type $\omega_{a}(\theta)$ is strictly increasing in 
the type of the politician, $\frac{\partial \omega_{a}}{\partial \theta}>0$, so that the signal is at least somehow informative of the ability of the politician. A particular case (used by Poutvaara and Takalo, 2007) is that a candidate of type $\theta_{i}$ has a probability $\theta_{i}$ of sending a high signal, with $\frac{\partial \omega_{a}}{\partial \theta}=1$. We also assume that the utility of citizens strictly increases with the share of projects delivered at low $\cos t \lambda$, so that in equilibrium citizens voting sincerely randomize with equal probability among all the candidates observed as high type $a$. Hence, in equilibrium only candidates observed as high type have votes cast for their names. If too many (or not enough) candidates have votes, the ties are broken randomly.

We find that a good quality of the signal observed by voters can be enough to convince more able citizens to enter politics even if $M B_{\theta}<M C_{\theta}$. This is because the probability that the cost of campaigning is wasted is lower for the most able candidates. In that sense, better-informed voters solve a large part of the selection problem. The impact of the cost of campaigning is ambiguous. A higher cost means that campaigning is more expensive for everyone. Hence, if the pool of candidates is composed of the most able citizens, a higher cost of campaigning always increases the quality of the pool. However, if the candidates are the least able citizens and if the threshold politician is above the average type, an increase in the cost of campaigning actually decreases the quality of the pool of politicians (and of the elected politicians).

\subsection{Asymmetric errors in court assessments and court severity}

In the main part of the paper, we define the quality of accounting and judicial courts by $p$ and $q$ respectively. When we refer to "better courts" we thus have in mind more resources for the judicial system, resources that symmetrically decrease the number of false positives and false negatives in court rulings. An alternative view could be to consider the "severity" of a court. Denote by $p_{h \mid h}$ the probability of an accounting court correctly reporting a high cost and $p_{l \mid l}$ correctly reporting a low cost. Similarly, $q_{g \mid g}$ is the probability of a judicial court correctly reporting corruption and $q_{n g \mid n g}$ correctly reporting no corruption. Without any further assumptions, more severe courts means that the probability of being reported as high cost $p_{h \mid \text {. }}$ or guilty $p_{g \mid \text {. }}$ increases.

We find that the threshold at which a politician starts accepting bribes remains independent of her type. As the probability of being in a high state is higher for the high types, it therefore remains true that high types benefit more from corruption. More severe judges therefore decrease the advantage of being a high type - as in the main model - if and only if they deter corruption for a given pool of politicians. What is necessary is that the probability of being reported as guilty when innocent does not increase much more than the probability of being reported as guilty when actually guilty. If judges become so severe that the difference in the probability of being 
found guilty when guilty and when innocent decreases too much, then more severe judges increase corruption for a given pool of politicians.

\subsection{Decoupling the ability to benefit from corruption from the ability to deliver at low cost}

An important assumption of our main model is that corruption implies delivering at high cost a project that could otherwise have been delivered at low cost. This implies that politicians of greater ability find more ways to benefit from corruption. In this subsection, we consider a variant of the model in which the ability to benefit from corruption is completely independent from general competence. This could correspond to cases in which corruption consists simply of the passive action of accepting a bribe, or if the skills required to be good at corruption and good at delivering procurement projects are mutually independent.

Consider the following modification of the main model. A politician knows her type $\theta_{i}$ but, before learning the cost of a project, is offered the possibility of corruption with some probability. If she accepts corruption, the benefit is as before. If she refuses corruption, the actual cost is realized, $c_{l}=0$ with probability $\theta_{i}$ and $c_{h}$ otherwise. Thus, the choice to accept corruption or not is not the same for all abilities. By refusing corruption, the more able politicians are less likely to be found guilty, while the less able politicians more often take the risk of delivering at high cost and being erroneously convicted by a judge. Hence, the less able politicians are the most likely to accept corruption.

It is possible to show that better judicial courts have an ambiguous impact on the marginal benefit of being of high ability. This is because better judges protect low types (as before), but also decrease their benefits from corruption. As the low types are more likely to accept corruption, the impact is not unambiguously negative, as it is in the main model, depending on which effect dominates. Regarding accounting courts, a higher $p$ always increases the marginal benefit of being a high type. As in the main model, it increases the advantage of being more able conditional on not stealing. Unlike in the main model, its lowering of corruption affects low types disproportionately.

\subsection{Preference for corruption}

Finally, consider the possibility that not all citizens have the same preference for corruption. Assume that each citizen $i$ is characterized by an ability $\theta_{i}$ as before, but also a discount factor $\delta_{i}$ on revenue from corruption. A factor $\delta_{i}=1$ denotes a politician who has no moral problem with corruption (as in the main model), while $\delta_{i}=0$ is a perfectly honest politician. 
If $\delta_{i}$ is correlated with ability, this effect needs to be taken into account. In particular, if politicians of low ability are also more intrinsically dishonest, $\delta_{i}$ is negatively correlated with $\theta_{i}$, so that $s_{i}^{*}$ increases with $\theta_{i}$. The most able politicians are more often in a position to accept bribes (because they are more competent) but accept a smaller proportion of the bribes offered to them (because they are more honest). If this effect is sufficiently high, it is possible that less able politicians benefit more from corruption even if they are less likely to find themselves in a position to do so. In that case, the impact of $q$ on $M B_{\theta}$ becomes ambiguous: better judges protect the least able politicians as in the main model, but decreasing corruption may affect them more negatively.

\section{Conclusion}

This model is a first attempt to examine the role of judicial and accounting courts in efforts to reduce cost inefficiencies resulting from distorted procurement processes. A contribution of the paper is to disentangle the respective impact of corruption and incompetence on public procurement to suggest how courts might best use the information available to them to distinguish between the two factors as cost drivers.

Two insights stand out. The first is that policies designed to improve procurement outcomes have an impact on the types of individuals who enter politics (or become political appointees) and that this, in turn, affects procurement outcomes. This explains why a policy designed to strengthen a specific court responsible for monitoring procurement processes may have positive or negative effects on the cost-efficiency of those processes - for example, over time the presence of the court may lower the quality of the pool of politicians. This is a testable prediction: comparing a country in which politicians are of low ability relative to the general population to a country in which they are of high ability, the impact of common policies adopted to improve procurement, such as budgetary allocations to judicial or accounting courts or a change in the remuneration of politicians, should be different.

The second important policy insight is that fighting corruption in order to improve the efficiency of procurement processes can be misleading. Our model does not necessarily predict a tradeoff between corruption and competence: Policies designed to improve the pool of politicians may decrease corruption and improve cost efficiency in some cases but make matters worse in others. More specifically, our model predicts that, in situations where corruption is an important source of income for politicians, focusing on identifying dishonest politicians without performing comprehensive cost assessments may appear efficient, as it decreases the share of corrupt projects, 
but such a focus may actually raise overall costs by driving the most talented politicians away, leaving those of lesser skill supervising procurement.

As shown in Section 6, these two insights are affected differentially at the margin by alternative modelling assumptions. They also deserve further analysis to account for several real-world circumstances. We highlight six such circumstances that may affect our broad conclusions. These represent potential areas for further research.

First, while in our model, corruption is completely determined by the behaviour of the politician, in practice, it is also influenced by the firms executing the contract. As suggested by Auriol et al. (2016), the possibility of corruption in public procurement affects the quality of entrepreneurs applying for these contracts. One of the benefits of fighting corruption should be, then, that fewer firms offer bribes. This might be because firms are deterred from offering bribes by the increased risk of being found out. Or it might be because of changes in the self-selecting pool of firms electing to participate in public procurements. These changes would affect the scope for corruption among politicians in our model as well as the bargaining power of the two sides of the market.

Second, in many countries, politicians have a say in the staffing of judicial and accounting courts. Moreover, in some countries, courts may themselves be players of the game and get involved in choosing the policy options rather than simply focusing on measuring costs and monitoring noncompliance. For instance, if auditors have a clear political affiliation, this may give politicians some margin for setting the standards of cost assessments. Similar observations can be made about political factors in court appointments (including appointments to the supreme courts of the United States or Spain, for instance) and in the definition of guidelines on conflict of interest to be applied to judges. Such political factors open the door to deal-making and other forms of distortion not picked up by our model.

Third, we ignore the possibility that politicians may bribe the courts. In that case, giving more power to courts by increasing the level of punishment they are able to mete out may simply translate into higher bargaining power for the court to use to extort rents from politicians. Moreover, if more skillful politicians are also more able to fool the courts, they may benefit even more from corruption: first because they are more often in a position to extract rents, and second because their probability of being caught will be lower. It would therefore make sense to look into the impact of political influence on the role and effectiveness of judicial and accounting courts. Besley and Coate (2003) develop this idea by contrasting direct elections of regulators with political appointment, but more work is probably needed to refine the assessment of the scope and limits of these courts in reducing moral hazard and adverse selection in public procurement processes. 
Fourth, we ignore the possibility that politicians may avoid committing to anything which could negatively affect their performance. This would also bias procurement outcomes and possibly reduce public sector performance in yet another way. Unless voters put pressure on candidates to take a transparent position on the choices they make, it is very likely that the political agenda will be manipulated by the politicians, whether corrupt or incompetent, and that the cost and overall effectiveness of public procurement processes will be negatively affected.

Fifth, we assume that the probability of being in a position to deliver a project at low cost is exogenous. If being in such a position were the consequence of politicians' effort, and if effort is less costly for the most able politicians, the general idea that the latter will exert more effort and have more opportunities for corruption would hold. In that case, the impact of better judges would be to decrease the level of effort, because (i) a marginal amount of extra effort would be less likely to decrease the probability of judicial error and (ii) bribes would be less often accepted. The impact of better accounting courts is ambiguous, as (i) politicians who deliver projects at high cost are more often victims of judicial mistakes and (ii) bribes are less often accepted. Just as in the rest of the paper, the selection effects will depends on whether $M B>M C$ and whether the marginal politician is made better or worse off.

Finally, we assume the quality of the courts to be independent of the number of cases they treat. For a given budget, judges may however make less precise assessments if the number of projects reported at a high cost increases. Hence, when more incompetent citizens become politicians, the number of cases reported at a high cost increases, and the precision of the assessment by judges decreases. This in turn makes politics relatively more attractive to high ability citizens, as it reduces the protection of incompetence by the judicial system, and increases the incentives for corruption.

These observations illustrate the difficulty of coming up with a holistic view of the interactions between court institutions and procurement outcomes. But they also imply that we are likely to have simply underestimated the role of courts, both their scope and their limits, as drivers of procurement outcomes. This actually reinforces our main message. In public procurement, as in many policy issues, good intentions in the design of institutions and in the choice of instruments based on intuition have their limits. Unless complex interactions are accounted for, good intentions can lead to perverse effects. In the context of this paper, good intentions, simplistically implemented, distort the pool of politicians from which voters can choose; and from that point on, they can work against the public service goals that public procurement processes are expected to deliver. 


\section{Bibliography}

Antonakis, J. and Dalgas, O. (2009). Predicting elections: Child's play! Science, 323 (5918), $1183-1183$.

AURIOL, E. (2006). Corruption in procurement and public purchase. International Journal of Industrial Organization, 24 (5), 867-885.

—, Straub, S. and Flochel, T. (2016). Public procurement and rent-seeking: the case of Paraguay. World Development, 77, 395-407.

Bandiera, O., Prat, A. and Valletti, T. (2009). Active and passive waste in government spending: evidence from a policy experiment. The American Economic Review, 99 (4), 1278 1308.

Benito, B., Bastida, F., Ríos, A.-M. and Vicente, C. (2014). The causes of legal rents extraction: evidence from spanish municipalities. Public Choice, 161 (3-4), 367-383.

Berggren, N., Jordahl, H. and Poutvaara, P. (2010). The looks of a winner: Beauty and electoral success. Journal of Public Economics, 94 (1), 8-15.

—, - and - (2017). The right look: Conservative politicians look better and voters reward it. Journal of Public Economics, 146, 79-86.

Besley, T. (2005). Political selection. The Journal of Economic Perspectives, 19 (3), 43-60.

— and CoATE, S. (1997). An economic model of representative democracy. The Quarterly Journal of Economics, pp. 85-114.

— and - (1998). Sources of inefficiency in a representative democracy: a dynamic analysis. American Economic Review, pp. 139-156.

— and - (2003). Elected versus appointed regulators: Theory and evidence. Journal of the European Economic Association, 1 (5), 1176-1206. 
— and SMART, M. (2007). Fiscal restraints and voter welfare. Journal of public Economics, 91 (3), $755-773$.

Best, M. C., HJort, J. and Szakonyi, D. (2017). Individuals and Organizations as Sources of State Effectiveness, and Consequences for Policy. Tech. rep., National Bureau of Economic Research.

BraEndle, T. (2015). Does remuneration affect the discipline and the selection of politicians? evidence from pay harmonization in the european parliament. Public Choice, 162 (1-2), 1-24.

Caselli, F. and Morelli, M. (2004). Bad politicians. Journal of Public Economics, 88 (3), 759-782.

Compte, O., Lambert-Mogiliansky, A. and Verdier, T. (2005). Corruption and competition in procurement auctions. Rand Journal of Economics, pp. 1-15.

Dal Bó, E., Finan, F., Folke, O., Persson, T. and Rickne, J. (2017). Who Becomes a Politician? Tech. rep., National Bureau of Economic Research.

Di Tella, R. and Rotemberg, J. J. (2016). Populism and the Return of the ÒParanoid StyleÓ: Some Evidence and a Simple Model of Demand for Incompetence as Insurance against Elite Betrayal. Tech. rep., National Bureau of Economic Research.

EstaCHE, A. (2011). (ed.) Emerging Issues in Competition, Collusion, and Regulation of Network Industries. CEPR.

FERraZ, C. and FinAN, F. (2009). Motivating politicians: The impacts of monetary incentives on quality and performance. Tech. rep., National Bureau of Economic Research.

— and - (2011). Electoral accountability and corruption: Evidence from the audits of local governments. The American Economic Review, 101 (4), 1274-1311.

FoltZ, J. D. and OpokU-AgYemang, K. A. (2015). Do higher salaries lower petty corruption? a policy experiment on West Africa's highways.

GAgliarduCCI, S. and NANNICINI, T. (2013). Do better paid politicians perform better? disentangling incentives from selection. Journal of the European Economic Association, 11 (2), 369-398. 
—, — and Naticchioni, P. (2010). Moonlighting politicians. Journal of Public Economics, 94 (9), 688-699.

Hamermesh, D. S., Biddle, J. E. et al. (1994). Beauty and the labor market. American Economic Review, 84 (5), 1174-94.

HoffMAn, M. and LyOnS, E. (2015). Do higher salaries lead to higher performance? evidence from state politicians. In Academy of Management Proceedings, Academy of Management, vol. 2015, p. 19175.

Kotakorpi, K. and Poutvaara, P. (2011). Pay for politicians and candidate selection: An empirical analysis. Journal of Public Economics, 95 (7), 877-885.

LAMBerT-Mogiliansky, A. (2015). Social accountability to contain corruption. Journal of Development Economics, 116, 158-168.

Mattozzi, A. and Merlo, A. (2008). Political careers or career politicians? Journal of Public Economics, 92 (3), 597-608.

Myerson, R. B. (1993). Effectiveness of electoral systems for reducing government corruption: a game-theoretic analysis. Games and Economic Behavior, 5 (1), 118-132.

OECD (2016). Preventing corruption in public procurement.

Osborne, M. J. and Slivinski, A. (1996). A model of political competition with citizencandidates. The Quarterly Journal of Economics, pp. 65-96.

Peichl, A., Pestel, N. and Siegloch, S. (2013). The politicians' wage gap: insights from german members of parliament. Public Choice, 156 (3-4), 653-676.

Poutvaara, P. and Takalo, T. (2007). Candidate quality. International Tax and Public Finance, 14 (1), 7-27.

SMART, M. and Sturm, D. M. (2013). Term limits and electoral accountability. Journal of Public Economics, 107, 93-102.

SøReIDE, T. (2002). Corruption in public procurement. Causes, consequences and cures. Chr. Michelsen Intitute.

Todorov, A., Mandisodza, A. N., Goren, A. and Hall, C. C. (2005). Inferences of competence from faces predict election outcomes. Science, 308 (5728), 1623-1626. 
VAN Veldhuizen, R. (2013). The influence of wages on public officials' corruptibility: A laboratory investigation. Journal of economic psychology, 39, 341-356.

WiNTERS, M. S. and WEITZ-SHAPIRO, R. (2013). Lacking information or condoning corruption: When do voters support corrupt politicians? Comparative Politics, 45 (4), 418-436. 


\section{Appendix A: Proofs}

\section{Proof of Lemma 1}

Proof. To find $\hat{s}$ one needs to find the smallest value of $s$ such that stealing is preferred to not stealing, solving

$$
s c_{h}-\gamma p q \geq-\gamma(1-q)(1-p) .
$$

As $s \in\{0,1\}$, we also need to look for corner solutions. As the support of $s$ is $[0,1], s^{*}=1$ whenever $\hat{s} \geq 1$. There is no corner solution $s=0$ as $\hat{s} \geq 0$ for all $p, q \geq \frac{1}{2}$.

\section{Proof of Proposition 1:}

Proof. The sign of $M B_{\theta}-M C_{\theta}$ determines the direction of the inequality. If $M B_{\theta}>M C_{\theta}$, equation (3) can be rewritten as

$$
\theta \geq \frac{-U_{0}(j)}{M B_{\theta}-M C_{\theta}}=\hat{\theta}
$$

If $M B_{\theta}<M C_{\theta}$, equation (3) can be rewritten as

$$
\theta \leq \frac{-U_{0}(j)}{M B_{\theta}-M C_{\theta}}=\hat{\theta}
$$

We also need to define $\theta^{-}=\max \{\hat{\boldsymbol{\theta}}, 0\}$ and $\theta^{+}=\min \{\hat{\boldsymbol{\theta}}, 1\}$ in order to take into account corner solutions, as $\theta \in[0,1]$.

\section{Proof of Proposition 2:}

Proof. If $\hat{\theta} \in(0,1)$ has an interior solution, the quality of politician decreases with the quality of the signal sent by judges if $\frac{\partial \hat{\theta}}{\partial q} \leq 0$, as it makes the pool of politicians less selective if $M B_{\theta}>M C_{\theta}$ and more selective otherwise. It is easy to show that $\frac{\partial \hat{\theta}}{\partial q} \leq 0$ if and only if

$$
-\frac{\partial U_{0}(j)}{\partial q}\left(M B_{\theta}-M C_{\theta}\right)+\frac{\partial M B_{\theta}}{\partial q}\left(U_{0}(j)\right) \leq 0 .
$$

If $\hat{\theta} \in(0,1)$, it must be that $\left(-U_{0}(j)\right)$ and $\left(M B_{\theta}-M C_{\theta}\right)$ are of identical sign. Hence, (26) rewrites

$$
\frac{\partial M B_{\theta} / \partial q}{M B_{\theta}-M C_{\theta}} \geq \frac{\partial U_{0}(j) / \partial q}{U_{0}(j)}
$$


where $\hat{\theta}=\frac{-U_{0}(j)}{M B_{\theta}-M C_{\theta}}$. If $\hat{\theta} \notin(0,1)$, the statement is trivial has either all or no citizen enter the pool of politicians depending on the value of $U_{0}(j)$.

\section{Proof of Proposition 6}

Proof. There is no corruption if and only if $s^{*} \geq 1$, which using Lemma 1 and $p=1, q=\frac{1}{2}$ simplifies to $\gamma \geq 2 c_{h}$. Only the most able citizens choose to enter when $M B_{\theta}>M C_{\theta}$, which, when $s^{*}=1, p=1$ and $q=\frac{1}{2}$ simplifies to $\gamma>2 \bar{w}$. Finally, when $s^{*}=1, p=1$ and $q=\frac{1}{2}$ the most able politician $\theta=1$ prefers to join the pool of politicians if and only if $w_{0} \geq \bar{w}$. 